\title{
General paper \\ Effect of Molecular Weight on Fatigue Characteristics of Ultra-High Molecular Weight Polyethylene for Implant Material
}

\author{
Lei Wang*, Mitsuo Ninomi**, Takumi EnJITSU** and Kei-ichi Fununaga** \\ * Department of Mechanical Engineering, Tottori University, Koyama 4-101, Tottori 680-8552, Japan \\ **Department of Production Systems Engineering, Toyohashi University of Technology, \\ Tempaku-cho 1-1, Toyohashi 441-8580, Japan
}

\begin{abstract}
In order to investigate the effect of molecular weight on fatigue characteristics in the ultra-high molecular weight polyethylene (UHMWPE), tension-tension fatigue tests of notched specimens were carried out in the present study. The effects of testing parameters were investigated and fractography was also discussed. The fatigue strength does not increase with increasing molecular weight. The fatigue strength might be influenced by the high degree of crystallinity in spite of the decreased tie molecular density. Almost no effect of frequency on the number of cycles to failure can be observed. However, the higher the frequency is, the higher the crack tip temperature. At high stress ratio, number of stress cycles to failure (S-N) curves shift to the side of high number cycles to failure.
\end{abstract}

Key words: Molecular weight, Fatigue, Ultra-high molecular weight polyethylene, Frequency, Stress ratio

\section{INTRODUCTION}

Ultra-high molecular weight polyethylene(UHMWPE) has been used as a biomaterial for replacing failed hard tissue because of its excellent impact resistance, higher wear resistance and greater biocompatibility. For example, in the most advanced structure of artificial hip joint, UHMWPE is used for the socket contacted with the ceramic bone head composed of alumina or zirconia attached to the stem made of titanium alloys. Those parts are usually operated under the cyclic loading due to walking for a long time. Therefore, fatigue characteristics of UHMWPE are very important to prolong the life of the instrumentation like artificial hip joints used in the body. Since polyethylene is composed of crystalline and amorphous parts, its fatigue characteristics are influenced by various factors, and the fatigue life prediction is very difficult. Moreover, the fatigue problems are more complex because of the visco-elasticity.

Recently, some reports have been made on the fatigue characteristics of the polyethylene [1-5], and it was found that the molecular, degree of crystallization or tie molecule influence the fatigue characteristics. However, since these findings are very limited, it is necessary to understand the fatigue characteristics of UHMWPE in detail.

Fatigue strength and crack propagation tests were performed on UHMWPE with various molecular weights in order to investigate the influence of molecular weight on the fatigue characteristics in this study. The effects of testing parameters were also investigated and fractography was discussed.

\section{EXPERIMENTAL PROCEDURES}

\subsection{Materials}

The materials used in the present study are UHMWPE plates with a thickness of $10 \mathrm{~mm}$ fabricated by press forming. The molecular weight, density and average particle size of powder before press forming are listed in Table 1. Each material will be described as PE 575, PE 360, PE 230, PE 210 and PE 200, respectively in the order of molecular weight number, which indicates the molecular weight in this study. It is notable that the PE 210 has been fabricated using a bit smaller particles of powder with an average diameter of $130 \mu \mathrm{m}$ and a relatively narrow particle size distribution. PE 200 has been fabricated using much smaller particles of powders with an average diameter of $30 \mu \mathrm{m}$.

\subsection{Measurement of Degree of Crystallinity}

The degree of crystallinity of the testing materials was measured using a differential scanning calorimeter

Table 1. Characteristics of samples used in present study.

\begin{tabular}{l|c|c|c}
\hline Sample & $\begin{array}{c}\text { Average } \\
\text { molecular weight, } \\
\mathrm{g} / \mathrm{mol}\end{array}$ & $\begin{array}{c}\text { Density, } \\
\mathrm{g} / \mathrm{cm}^{3}\end{array}$ & $\begin{array}{c}\text { Average-particle } \\
\text { size, } \mu \mathrm{m}\end{array}$ \\
\hline PE575 & $575 \times 10^{4}$ & 0.929 & 160 \\
PE360 & $360 \times 10^{4}$ & 0.934 & 150 \\
PE230 & $230 \times 10^{4}$ & 0.935 & 160 \\
PE210 & $210 \times 10^{4}$ & 0.937 & 130 \\
PE200 & $200 \times 10^{4}$ & 0.940 & 30 \\
\hline
\end{tabular}


(DSC). The sample was cut from the plate with a weight of $5 \mathrm{mg}$, and measured within Ar gas atmosphere where it was heated up to $453 \mathrm{~K}$ at a heating rate of $10 \mathrm{~K} / \mathrm{min}$. The heat of fusion, $\Delta H \mathrm{~m}$, was calculated from the endothermic curve. Then the degree of the crystallinity, $W c(\%)$, was calculated using the Eq. (1):

$$
W c(\%)=100 \times \Delta H \mathrm{~m} / \Delta H
$$

where $\Delta H$ is the heat of fusion needed for complete crystallization of the polyethylene. $293 \mathrm{~J} / \mathrm{g}$ [2] was adopted as $\Delta H$ in the present study.

\subsection{Tensile and Fatigue Testing}

As the basic mechanical properties, the tensile test was first carried out using an Instron type testing machine at a cross head speed of $8.3 \times 10^{-4} \mathrm{~m} / \mathrm{s}$. The specimens without notch whose geometry is shown in Fig. 1 were machined from the plate.

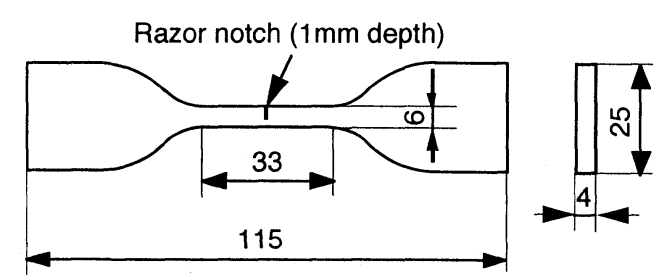

Fig. 1. Geometry of tensile (without notch) and fatigue (with notch) specimen.

The specimens with a razor notch (shown in Fig. 1) whose depth is $1 \mathrm{~mm}$ were used for fatigue tests. The tests were performed in air at a temperature of $296 \pm 1 \mathrm{~K}$ with a sine wave under a constant loading condition using a servo-hydraulic testing system. The stress ratio, $R$, and the frequency, $f$, were in general 0.1 and $1 \mathrm{~Hz}$, respectively. In order to investigate the effects of the stress ratio and the frequency on the fatigue behavior, the tests were also carried out under $R=0.5$, and $f=3$ and $5 \mathrm{~Hz}$.

Fatigue crack propagation characteristics were investigated by the same system with that of fatigue test, using the single side notched specimen $(4 \times 25 \times 110$ $\mathrm{mm}^{3}$ ) with a notch depth of $5 \mathrm{~mm}$. The crack lengths were measured after certain cyclic numbers by an optical microscope with a special moving stage.

\subsection{Fracture Surface Observation}

The fracture surfaces were coated with platinum, and were then characterized using a scanning electron microscope (SEM).

\section{RESULTS AND DISCUSSION}

\subsection{Tensile Characteristics}

The tensile properties, degree of crystallinity and melting temperature of the materials are shown in Table 2. The tensile strength and melting temperature of $\mathrm{PE}$ 230 are a little lower than those of the other materials. The other materials except PE 230 have nearly the same tensile strength and melting temperature. However, the elongation of the materials decreases with increasing molecular weight. Meanwhile, the degree of crystallinity of the materials also decreases with increasing molecular weight, because the heat of fusion decreases with increasing molecular weight, according to Eq. (1).

The typical load-elongation curve obtained in tensile test is shown in Fig. 2. The slope of the curve after yield point increases with increasing molecular weight. In other words, the work hardening ratio of the material increases with increasing molecular weight. This may be caused by increasing the tangling of molecular chains with increasing molecular weight of the material.

The typical SEM fractographs of PE 210 after tensile test are shown in Fig. 3. It can be seen from Fig. 3 (a) taken at low magnification that the crack initiates at specimen surface. The crack propagates from the initiation

Table 2. Tensile properties, crystallinity and melting temperature of samples.

\begin{tabular}{c|c|c|c|c|c}
\hline Sample & $\begin{array}{c}\text { Yield } \\
\text { strength } \\
\sigma_{y}, \mathrm{MPa}\end{array}$ & $\begin{array}{c}\text { Tensile } \\
\text { strength } \\
\sigma_{\mathrm{F}}, \mathrm{MPa}\end{array}$ & $\begin{array}{c}\text { Elongation } \\
E_{1}, \%\end{array}$ & $\begin{array}{c}\text { Degree of } \\
\text { crystallinity } \\
W_{\mathrm{c}}, \%\end{array}$ & $\begin{array}{c}\text { Melting } \\
\text { temperature } \\
T_{\mathrm{m}}, \mathrm{K}\end{array}$ \\
\hline PE575 & 22.7 & 43.3 & 374 & 48.5 & 410.0 \\
PE360 & 23.0 & 41.1 & 431 & 50.3 & 410.6 \\
PE230 & 21.2 & 34.0 & 511 & 51.1 & 398.5 \\
PE210 & 24.0 & 40.4 & 504 & 52.9 & 410.7 \\
PE200 & 23.1 & 40.6 & 506 & 53.2 & 411.1 \\
\hline
\end{tabular}

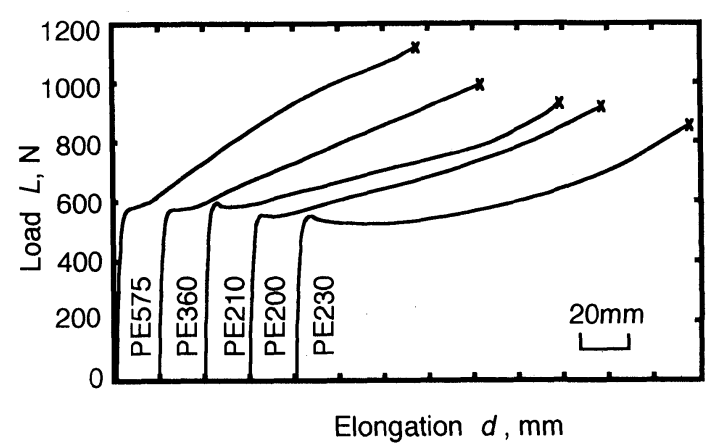

Fig. 2. Typical load - elongation curve of testing materials. 


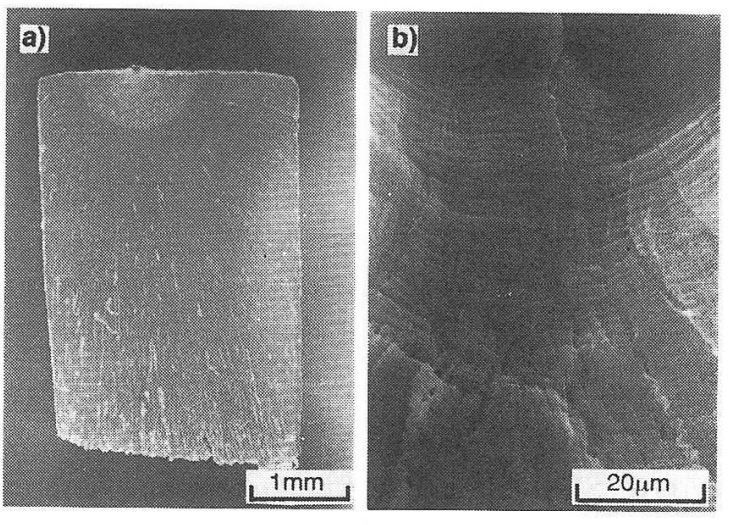

Fig. 3. SEM micrographs of typical tensile fracture surface (PE210).

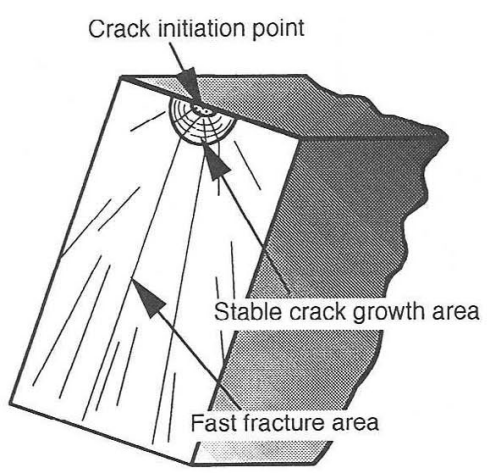

Fig. 4. Tensile fracture schematic diagram of UHMWPE.

site with creating striped pattern in the stable crack propagation state (Fig. 3 (b)). Based on the fracture surface observation, the tensile fracture surface morphology of the UHMWPE can be schematically illustrated in Fig. 4. The fracture process can be divided into three stages: the crack initiation, stable propagation and unstable crack propagation stages. This fracture morphology is similar to that of the nylon-filament, which has been reported by Ogata and Yoshida [6].

\subsection{Fatigue Strength}

The typical S-N curve is shown in Fig. 5. Among the tested materials, PE 200 and PE 210 are superior to the other materials in fatigue strength. In general, the larger the molecular weight, the greater the fatigue strength [1]. However, it does not hold in the present materials. For instance the degree of crystallinity, the size or size distribution of powder at press forming will influence the fatigue behavior.

Iwamoto and Jinen [4] have reported that high degree of crystallinity leads to fatigue strength, while Runt

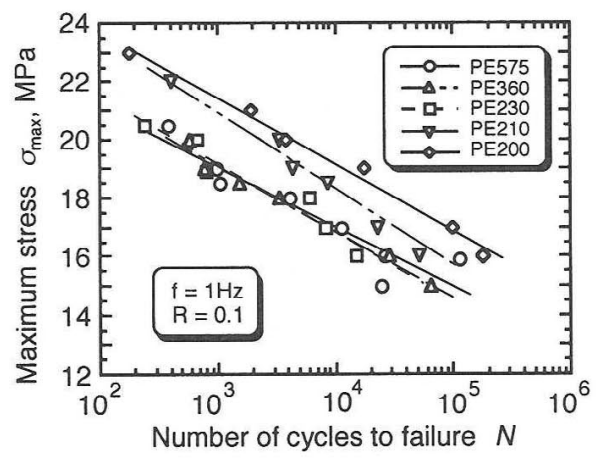

Fig. 5. Relationship between maximum stress, $\sigma_{\text {max }}$ and number of cycles to failure.

et al. [2,3] have found that low degree of crystallinity results in lower fatigue strength.

On the other hand, Yen et al. [7] pointed out that the fatigue strength is related to tie molecules. The tie moleculcs are formed in the non-crystalline part, and connect the crystalline parts (Fig. 6), which are related to both the fracture of crystalline part and the strength of noncrystalline parts. Runt [2] and Strebel [3] have re-ported that the fatigue strength increased with increasing number of tie molecular chains. However, it is very difficult to measure the tic molecular density. Brown and Ward [8] have successfully calculated the tie molecule chain density , $f_{\mathrm{T}}$, with the brittle fracture stress, $\sigma_{\mathrm{B}}$, at low temperature by the following equation :

$$
f_{\mathrm{T}}=\left(C \sigma_{\mathrm{B}}-\beta E_{\mathrm{ISO}}\right) / \beta\left(E_{\mathrm{T}}-E_{\mathrm{ISO}}\right)
$$

where $E_{\mathrm{T}}$ is the Youngís modulus of the tie molecules, $E_{\text {ISO }}$ is the Youngís modulus in Van der Waals bonding, $\beta$ is the constant, and $C$ is the stress concentration factor. For the present materials, $E_{\mathrm{T}}=300 \mathrm{MPa}, E_{\mathrm{ISO}}=8 \mathrm{GPa}$, $\beta=0.1$, and $C=20$ [8], and the brittle fracture stress, $\sigma_{\mathrm{B}}$, obtained from the tensile tests in liquid $\mathrm{N}_{2}$ is shown in Table 3 . The tie molecule chain density, $f_{\mathrm{T}}$, calculated by the Eq. (2) is also shown in the same table. The brittle fracture strength, $\sigma_{B}$, is $3.5 \sim 4.7$ times greater than the tensile strength, $\sigma_{\mathrm{F}}$, at room temperature.

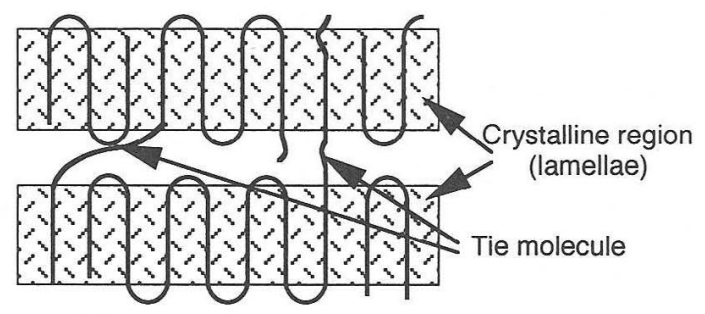

Fig. 6. Schematic drawing of tie molecule. 
Table 3. Brittle fracture stress $\sigma_{\mathrm{B}}$ and tie molecule density $f_{\mathrm{T}}$ of the testing materials.

\begin{tabular}{c|c|c|c|c|c}
\hline Sample & PE575 & PE360 & PE230 & PE210 & PE200 \\
\hline$\sigma_{\mathrm{B}}, \mathrm{MPa}$ & 157 & 157 & 160 & 143 & 146 \\
$f_{\mathrm{T}}$ & 0.080 & 0.080 & 0.082 & 0.071 & 0.073 \\
\hline
\end{tabular}

The relationship between molecular weight and the degree of crystallinity or the tie molecular chain density is shown in Fig. 7. The degree of crystallinity decreases with increasing molecular weight. For instance, the degree of crystallinity of PE 200 is much greater than those of others. However, the tie molecular chain densities of PE 200 and PE 210 are much smaller than those of others. Therefore, it can be seen that the fatigue strength of the present materials is strongly influenced by the degree of crystallinity rather than by the tie molecular chain density.

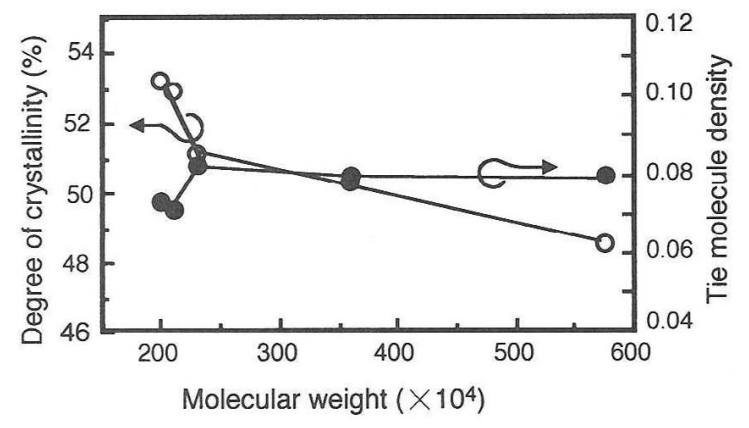

Fig. 7. Degree of crystallinity and tie molecule density as a function of molecular weight.

SEM fractograph of PE 360 as a representative observation result of fatigue fracture surface is shown in Fig. 8. The striation like cyclic patterns can be seen on the fracture surface perpendicular to the crack propagation direction. The striation like pattern seems to be different from that observed on the fatigue fracture surface of the metallic materials [9]. In the present materials, the fracture surface was firstly stretched by tear stress, then shrank and rolled in to form the striation like pattern as the crack propagates.

\subsection{Fatigue Crack Propagation}

Figure 9 shows the typical results of fatigue crack propagation test. The crack length of UHMWPE materials increased smoothly with increasing number of cycles. It seems that within the same fatigue life, there is no difference between the materials with different molecular weight, although the crack propagation rate of $\mathrm{PE}$ 575 decreased comparing with PE 210 and PE 200 near

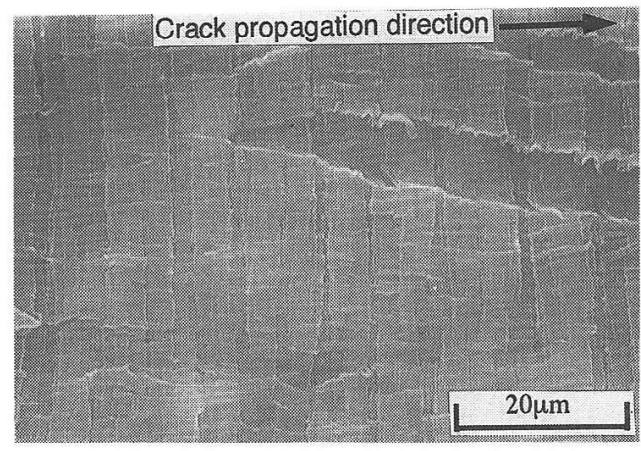

Fig. 8. SEM mirograph of fatigue fracture surface (PE360).

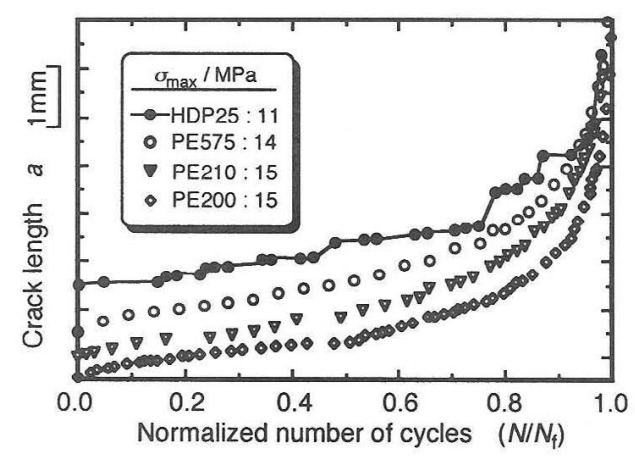

Fig. 9. Crack length as a function of normalized number of cycles with different materials at $R=0.1, f=1 \mathrm{~Hz}$.

the end of the fatigue life $\left(N / N_{\mathrm{f}}>0.9\right)$. However, it is clear that the behavior of fatigue crack propagation of the UHMWPE is quite different from that of the high density polyethylene (HDP 25). Thus, the crack length of HDP 25 increased intermittently. This phenomenon can be explained by the difference in the crack tip, which is shown in Figs. 10 (a) and (b), respectively. The craze, which is intrinsic in polymer materials [10], can be observed near the crack tip of usual polyethylene as shown in Fig. 10 (b). However, the large failed region such as craze can not be observed near the crack tip of present UHMWPE as shown in Fig. 10 (a). This trend has also been confirmed by the SEM observation of fracture surface (see Figs. 10 (c) and (d)).

\subsection{Effect of Testing Parameters on Fatigue Behavior}

In general, since the polymers have lower heat conductivity, the temperature of the specimen is raised by the cyclic deformation, and the fatigue strength is influenced by frequency [11] and the strain rate due to its viscoelasticity [8]. Bucknall and Dumpleton [12] have reported that the number of cycles to failure increases with the frequency, $f$, between 0.5 and $2 \mathrm{~Hz}$ in the fatigue 

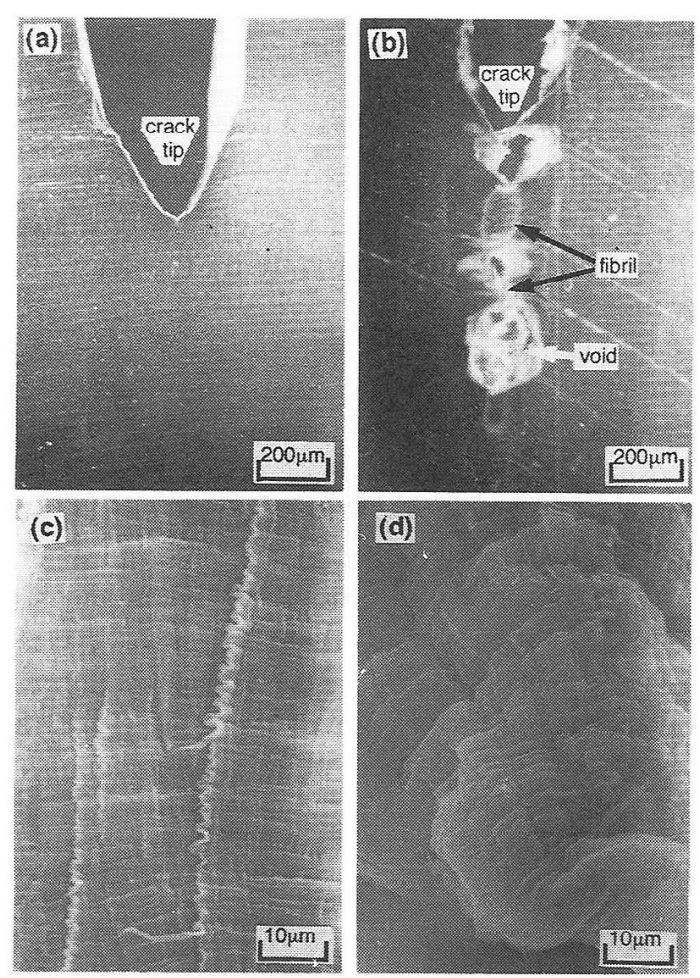

Fig. 10. Optical micrographs of crack tip regions, showing the difference in front of the crack tip, (a) without, (b) with craze. And SEM micrograph of fracture surface in the stable crack propagation stage. The molecular weight of the specimens is $210 \times 10^{4}$ for (a) and (c), $25 \times 10^{4}$ for (b) and (d).

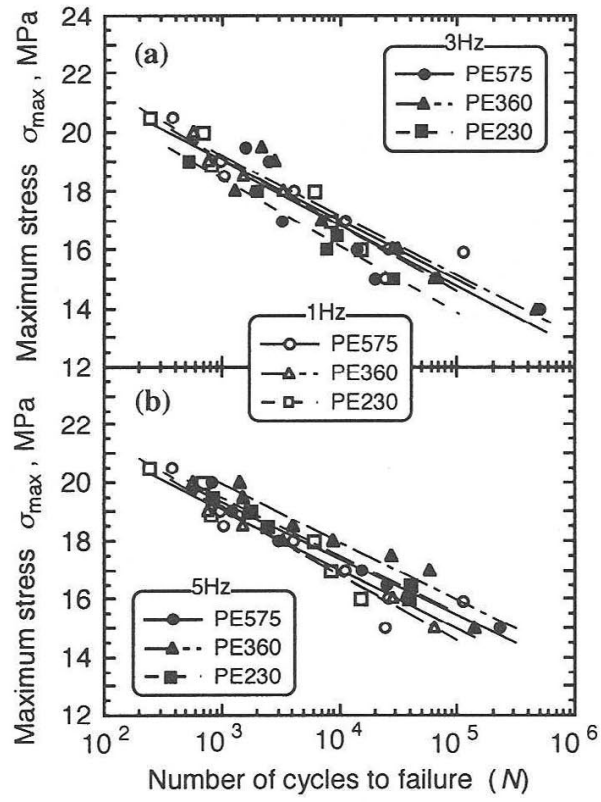

Fig. 11. Effect of frequency on S-N curve with a stress ratio of 0.1 . tests of the HDP. Figures 11 (a) and (b) show the S - N curves obtained at $f=3 \mathrm{~Hz}$ and $f=5 \mathrm{~Hz}$, respectively. For the comparison, the $\mathrm{S}-\mathrm{N}$ curves obtained at $f=1$ $\mathrm{Hz}$ are also shown in each figure. The fatigue strength obtained at $f=5 \mathrm{~Hz}$ looks a little greater than that obtained at $f=3 \mathrm{~Hz}$. However, the difference between them is very small. It can be said that the frequency dependency on the number of cycles to failure is not recognized in the present materials.

When the maximum stress is kept constant, the relationship between stress amplitude and number of cycles to failure with different stress ratio is shown in Fig. 12. The fatigue life of each material is longer at $R=0.5$ than that at $R=0.1$, also somehow the fatigue life increased with increasing molecular weight. Assuming liner viscoelasticity, the amount of heat generation per unit time due to the visco-elastic loss energy, $W$, is described by the following equation [13]:

$$
W=\pi f C^{\prime}(f, T) \sigma_{\mathrm{a}}^{2}
$$

where $C^{\prime}$ is the loss compliance, $T$ is the testing temperature, $f$ is the frequency, and $\sigma_{\mathrm{a}}$ is the stress amplitude. It is clear from the above equation that $W$ increases proportionally to the testing frequency, $f$, and to the square of stress amplitude, $\sigma_{\mathrm{a}}^{2}$. The equation suggests how the heat generation, that is, temperature rising of the specimen will be influenced by the testing parameters.

Sauer et al. [14] have pointed out that the effect of temperature on the mechanical properties of the polyethylene is strong. Therefore, the temperature change in the specimen during fatigue tests was also investigated in the present study. A thermoelectric-couple was put near the notch of the specimen surface of PE 360, and the temperature was recorded continuously. At the same time, the testing environment temperature was controlled to be constant at $293 \pm 0.5 \mathrm{~K}$. The results of the

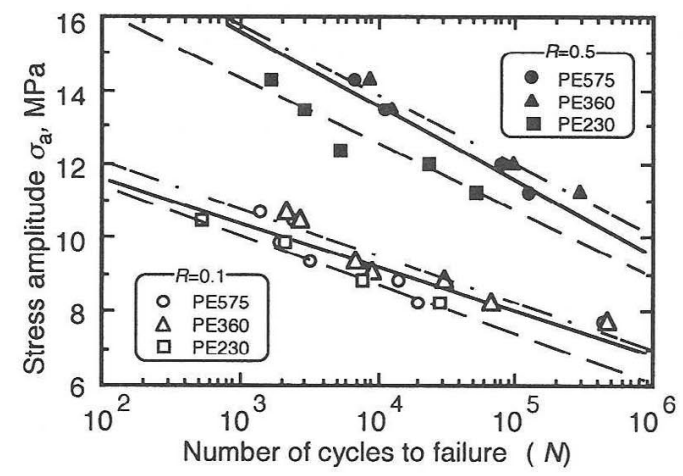

Fig. 12. Relationship between stress amplitude, $\sigma_{a}$, and number of cycles to failure with a frequency of $3 \mathrm{~Hz}$ at different stress ratios. 
measurement of temperature change near the crack tip of the specimen surface versus normalized number of cycles obtained in PE 360 at a constant maximum stress of $18 \mathrm{MPa}$ are shown in Fig. 13. The temperature changed during testing, and increased with increasing frequency. The temperature change can be divided into three stages as marked in the figure with I, II and III. The temperature rises at the steady stage II, for example, about $1 \mathrm{~K}$ at $f=1 \mathrm{~Hz}$, about $4 \mathrm{~K}$ at $f=4 \mathrm{~Hz}$, and about 6 $\mathrm{K}$ at $f=5 \mathrm{~Hz}$. In fact, the actual temperature at the crack tip of the specimen interior will rise much greater than that on the specimen surface. From this result, it can be suggested that the number of cycles to failure (the fatigue life) will increase with increasing strain rate due to the increase in frequency, while the fatigue life will be decreased by heating due to the heat accumulation with increasing frequency. These two effects will cancel each other, and the effect of frequency on fatigue strength will not be clearly recognized. Anyhow, the fatigue tests at high frequency are necessary to be carried out carefully because the temperature rising of the specimen is remarkable. The effects of stress state at the artificially introduced pre-crack tip and the visco-elastisity on the crack tip blunting is necessary to be taken into account in analyzing the results of fatigue tests with the effect of

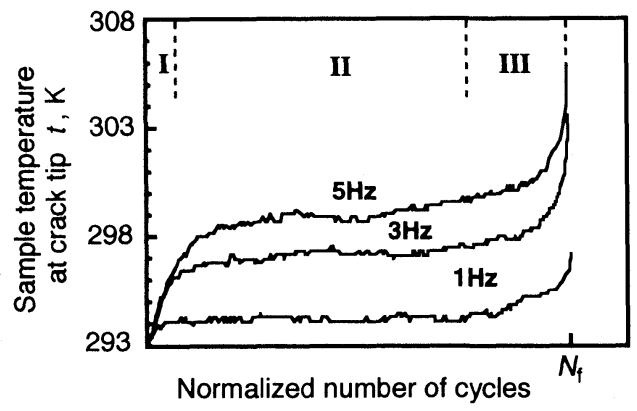

Fig. 13. Effect of frequency on crack tip temperature as a function of normalized number of cycles at a maximum stress of $18 \mathrm{MPa}$. frequency and temperature.

\section{CONCLUSIONS}

(1) The fatigue strength of the UHMWPE does not increase with increasing molecular weight. Fatigue strength will be influenced more strongly by the crystallinity than by molecular weight.

(2) The fatigue crack propagation rate of the UHMWPE is less influenced by the molecular weight. However, the crack propagation behavior is quite different with the high density polyethylene.

(3) Both the frequency and stress ratio influence the fatigue life. The fatigue life of the present materials increases with increasing stress ratio when the stress amplitude is plotted versus the number of cycles to failure. Since the frequency have both increasing strain rate and increasing heat accumulation effects, and these two effects will cancel each other on the number of cycles to failure (fatigue life), the effect of frequency on fatigue life will not be remarkable.

\section{REFERENCES}

1. H. Nishimura and I. Narisawa, Polym. Eng. Sci., 31 (1991) 399

2. J. Runt and M. Jacq, J. Mater. Sci., 24 (1989) 1421.

3. J. J. Strebel and A. Moet, J. Polym. Sci. Part B. Polym. Phys., 33 (1995) 1969.

4. M. Iwamoto and S. J. Jinen, J. Soc. Mater. Sci., Japan, 37 (1987) 807 (in Japanese).

5. X. Lu, R. Qian and N. Brown, Polymer, 36 (1995) 4239

6. N. Ogata and Y. Yoshida, J. Soc. Mater. Sci., Japan, 18 (1982) 240 (in Japanese).

7. J. T. Yen and J. Runt, J. Mater. Sci., 24 (1989) 2637.

8. N. Brown and I. M. Ward, J. Mater. Sci., 18 (1983)1405.

9. R. Koterazawa, Fractograph and its applications, Nikan Industry News Press, Tokyo, (1983) 34 (in Japanese).

10. J. J. Strebel and A. Moet, J. Mater. Sci., 26 (1991) 5671.

11. S. Nagai and S. Ishikawa, Proceedings of Polymer, 52 (1995) 125

12. C. B. Bucknall and P. Dumpleton, Polym. Eng. Sci., 25 (1985) 313.

13. R. W. Hertzberg and J. A. Monson, Proceedings of the 27th Sagamore Army Materials Research Conference, (1983) 231.

14. W L. Sauer, K. D. Weaver and N. B. Beals, Biomaterials, 17 (1996) 1929. 